\title{
Digital Modeling of Enterprise e-Business Model
}

\author{
Yuhui Feng $^{1}$ Zhiwu Dou ${ }^{1}$ \\ ${ }^{1}$ School of Business, Yunnan University of Finance and Economics, Kunming, China
}

\begin{abstract}
As the e-Business environment changing, the e-business models needs of ondemand and needs to adjust constantly throughout the life cycle. It is necessary that digital e-Business model. In this paper, research how to digital the e-business models into computer model. That is how to build the composition of e-business model, witch model selected, how to descript the digital model, and how to descript the model inter-face.
\end{abstract}

Keywords: Enterprise e-Business Model, Digital Modeling, Business Process

\section{INTRODUCTION}

Designing, innovation and transformation of e-Business model is an important part in e-Business activities. Now, the enterprise e-business is not only just Internet marketing, but also it has penetrated into enterprise business operational. Enterprise e-business model design and innovation activities are no longer racking our brains for ideas, but the process of combination, reconstruction by use of a series of results of successful business activity in the industrial operations (these results condensation as knowledge).

E-business model requires flexibility and involved in the entire operation process. In the changing economic and IT environment, enterprise e-business model can not be de-signed on a static, it need to be adjusted constantly with changes in the environment. E-business model re- quired by the iterative development life cycle, constantly, to combine business and IT, consistency and good ecology. It should participate in the entire process of business operations, continuous monitoring through dashboards, statistics, to continuous improvement.

As mentioned above, the design of ebusiness model re-quires that the use of existed knowledge (or reuse). Knowledge is a result of successful business activities, or as best practices. Only through digital, the knowledge into com-puter information media, it can be used in business activities effectively and easily. Digital e-commerce model is called e-mode.

Therefore, this paper discusses how to digital the e-business models into computer models. The idea is: build the composition of e-business models, model selection, digital model representation and e-Business model inter-faces.

\section{COMPOSITION OF E-BUSINESS MODEL}

To build the composition of e-business models can refer to the research on the elements of e-Business and combined with the characteristics of information technology.

\subsection{Research situation on element of e-Business Model}

Many scholars have researched on the composition of elements of e-Business models, the results shown in Table 1. 


\begin{tabular}{|c|c|}
\hline Researcher & Elements \\
\hline Mahadevan[1] & value flow, revenue flow and logistics flow \\
\hline Thomas[2] & $\begin{array}{l}\text { business processes, customers, suppliers, channels, resources and capabil- } \\
\text { ities }\end{array}$ \\
\hline Afuah et al[3] & $\begin{array}{l}\text { customer value, scope, price, source of income, related activities, execu- } \\
\text { tion and sustainability }\end{array}$ \\
\hline Pigneur[4] & $\begin{array}{l}\text { business, products, value proposition, target customers, how to submit } \\
\text { products, partners }\end{array}$ \\
\hline Dubsson-Toray, etc[5] & $\begin{array}{l}\text { products or services, relationship capital, infrastructure and partner net- } \\
\text { work, the financial situation. }\end{array}$ \\
\hline Applegate[6] & $\begin{array}{l}\text { description of the concept of opportunity; definition of capacity of the } \\
\text { resources required for concept into reality; measure of the return value to } \\
\text { investors and other stakeholders }\end{array}$ \\
\hline Chesbrough et al[7] & $\begin{array}{l}\text { value proposition, market segment, value chain structure, cost structure } \\
\text { and profit potential, value network location of enterprise, competitive } \\
\text { strategy }\end{array}$ \\
\hline Alt et al[8] & $\begin{array}{l}\text { task (including the total vision, strategic objectives and value proposi- } \\
\text { tion), structure (to determine which role and agent form business commu- } \\
\text { nity and industry, customer and product focus), processes (provide a more } \\
\text { detailed description of the tasks and structure), income (baseline of busi- } \\
\text { ness model), legal issues (not contrary to regulations and control meas- } \\
\text { ures), technologies (both support and constraints) }\end{array}$ \\
\hline Linder et al[9] & value proposition, operational processes, assets, capabilities, and relations \\
\hline Hoque et al[10] & $\begin{array}{l}\text { competition, product and services, customers, suppliers and distributors, } \\
\text { partners, marketing strategy, processes and organizational }\end{array}$ \\
\hline Hedman et al[11] & $\begin{array}{l}\text { customers, competitors, companies providing products or services, busi- } \\
\text { ness activities and organizations, resources, and factor markets and pro- } \\
\text { duction input, }\end{array}$ \\
\hline Mckay and Marshall & $\begin{array}{l}\text { (1) description of target customers and relationships, value proposition (2) } \\
\text { description of products or services (3) business process (4) resource re- } \\
\text { quirements (5) description of the supply chain, including suppliers and } \\
\text { partners (6) description of expected profit (revenue model), expected } \\
\text { costs, funding sources and estimated profits (financial viability) }\end{array}$ \\
\hline
\end{tabular}

Table 1: Research results of elements of e-Business models.

\subsection{Composition of e-Business Model}

These studies reveal the contents of composition of e-business models step by step, enabling e-business models from these descriptions. According to the characteristics of information technology we proposed composition of e-business model as follows:

(1) Functional Description

(2) Value Proposition

(3) Market Positioning and Segmentation

(4) Revenue Model

(5) Core Capabilities

(6) Network Structure of Valuechain \& Enterprise Positioning
(7) Business Process

From the digital point of view, (1) - (6) is a descriptive form. The first (1), the interface of the e-business models, which for the computer system read, understood and match; (2), (3), (4), (5) is the performance description of e-business models, generally for people read and understand, of course, if the Semantic Web become mature technology, it could also be part of the understanding by the machine; (6) If the value chain or supply chain have been digitized, it can be read by machines. (7) of the act is a description of the operation of e-business models, is a concrete manifestation of e-business models. 
The following is the composition description.

\section{1) Function Description}

Functional description provides a product or service description. It is the interface of the e-business models. Reading, understanding, service matchmaking, be calling or constitute a value chain by other computer systems. This requires a certain degree of standardization, as described by the standard.

Functional description of some of the elements may include the following:

- Model Name: That is this emode's name.

- Model Type: Description of which type of model the ebusiness model is. Currently no accepted classification of ebusiness standards. May include: network economy, network advertising, content, online shop, network direct sales, industry service, virtual community, enterprise overall e-business, new e-business model and so on.

- Industry classification: Description of which industry this eBusiness model is. Can refer to the appropriate standards.

At present the main industry classifications are:

- International Student Identity Card (ISIC)

- North American Industry Classification System (NAICS)

- Industrial classification for national economic activities (GB/T4754-2002)

- Global Industry Classification Standard GICS)

- FTSE global Classification System (FTSE)

These standards were adopted usually were GICS, while in China, many with "National Economy Industrial Classification" (GB/T4754-2002).

\section{2) Value Proposition}

Value proposition of the present ebusiness model can bring to the user what kind of benefits. It is instructed from the following aspects. Productivity and profitability, Cost, Increase efficiency, Convenience, Risk management, Appearance, Service, Experience of the evaluation process, Buying process, Additional Products/Services and availability of product residuals treatment. In addition, key performance indicators can also be (KPI) to assess the value proposition to customers.

At present this part can be text, variables and their values to describe.

\section{3) Market positioning and segmenta- tion}

Market positioning is targeting consumer groups, e-Business can target these groups have some common value. Market segmentation is the process of the definition of consumer groups.

Current this section still needs the text description.

\section{4) Revenue model}

Description of this e-business model how to get the revenue including the expected costs, funding sources and estimated profits (financial viability) and so on. Typical sources of sales revenue, transaction fees, commissions, service fees, advertising fees, will be fees.

At present this part of the content from the text, variables and values to describe.

\section{5) Core Capabilities}

Core capabilities are the relative scarcity of resources and service capability features, including the company to implement its business model required the configuration of resources and activities, show in the following three aspects. (1)Resources: Including tangible and intangible resources. Tangible resources 
include plants, equipment, network infrastructure and cash reserves. Intangible resources include patents, goodwill, brands, trade secrets, and customer and supplier relationships, the relationship between employees and the different forms of knowledge within the company, customer and market databases, selfdesigned software. (2)Competitiveness: Competitiveness of the company put its resources into customer value and profit capabilities. (3)Competitive advantage: comes from the company owned core competencies that other company difficult to obtain and imitate.

This part of the content use the text to descript

\section{6) Network Structure of Value-chain \& Enterprise Positioning}

That the companies involved in ebusiness model Established partnership networks for effectively providing value and achieving their commercial and this project location in the network. Network structure can be distributed, or may be commercial alliances. Network Roles include the upstream vendors / suppliers and downstream manufacturers / distributors, partners, and so on.

The content can be described by text or network topology, or business process diagram.

\section{7) Business Process}

Business process provide a more detailed description for is the enterprise internal task and structure. It is a concrete manifestation of business models. By running the business processes to execute the ebusiness.

\section{MODELLING OF E-MODE}

\subsection{Mainly Modelling methods}

There are hundreds of processes modelling methods. Over the years evolved, now just several mainly method can be used as following.

1) ARIS(ARchitecture of integrated Information Systems) advanced by Professor A.W.Scheer, the German University of Saarbraecken. IDS-Scheer founded that Professor Scheer created has developed a comprehensive modelling and analysis software tool ARIS (ARIS Toolsets) basic on ARIS. SAP the world's leading ERP developers inject capital into the company to become the ERP software implementation of the pre-ARIS for enterprise modelling, analysis, diagnos-tic tools. Therefore, ARIS methods and software tools in the enterprise modelling, business process reengineering are widely used.

2) ANSI flow chart symbols standard. ANSI / ISO 5807-1985 standard is "Information processing -- Documentation symbols and conventions for data, program and system flowcharts, program network charts and system resources charts", published by the American National Standards Institute and International Organization for Stan-dardization. It provides a series of graphics symbols and connectors. Fig 1 is part of the graphic symbol example.

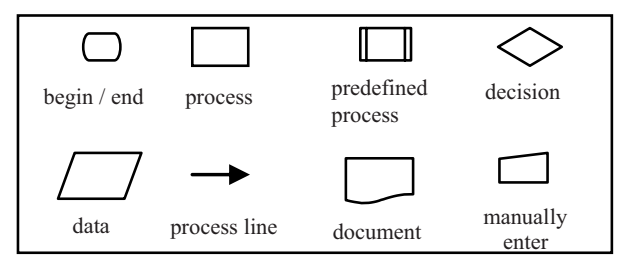

Fig. 1: ANSI flow diagram notation example.

3) IDEF notation. This is a modelling method used to de-scribe the enterprise internal operation. It was originally only applied in the manufacturing industry. Through the transformation, extension its use, also apply to general software devel- 
opment. There are a total of 16 sets of meth-ods systems. Each method is through the modelling process to obtain a specific type of information. The 16 sets of methods: IDEF0: Function Modelling, IDEF1: Information Modelling, IDEF1X: Data Modelling, IDEF2: Simulation Model Design, IDEF3: Process Description Capture), IDEF4: object-oriented design (Object-Oriented Design, IDEF5: Ontology Description Capture, IDEF6: Design Rationale Capture, IDEF7: Information System Auditing, IDEF8: User Interface Modelling, IDEF9: ScenarioDriven IS Design, IDEF10: Implementation Architecture Modelling, IDEF11: Information Artefact Modelling, IDEF12: Organi-zation Modelling, IDEF13: Three Schema Mapping Design, IDEF14: Network Design).

4) UML activity diagram, state diagram. UML (Unified Modelling Language) is the industry standard language. In 1997, It was published by the OMG (Object Management Group).It is a de facto industry standard. UML is used to specify, visualization, construction and Document software system components. UML offers a standard way to visual-ize a system's architectural blueprints, including elements such as: actors, business processes, (logical) components, activities, programming language statements, database schemas, and reusable software components. UML com-bines techniques from data modeling (entity relationship diagrams, ERD), business modeling (work flows), object modeling, and component modelling. Commonly used UML diagram are: Use case diagrams, Class diagrams, Sequence diagrams, Collaboration diagrams, State chart diagrams, Activity diagrams, Component diagrams and Deployment diagrams.

5) BPEL/BPMN. BPEL (Business Process Execution Lan-guage) is a new business process definition language that propose by industry based on the Specifi- cations of XML, Web Service, and so on. It based on interactive business process and its participants defined the business processes description syntax, for business process modelling. Among them, the interaction between business processes and their participants is described with Web Service interface stan-dard. So BPEL process can directly call the standard Web Service. The BPEL basic function is that can orchestrate and coordinate Web services. In 2007, OASIS (Organiza-tion for the Advancement of Structured Information Stan-dards) formally approved the BPEL standard, called WS-BPEL 2.0. WS-BPEL defines a set of basic activities that is used to create the Web services composition as follow: receive, reply, invoke, throw, exit, wait, and empty. WSBPEL document defines a set of Web services com-position is used to create the basic structure and con-tains the following elements. (1)partner link type, (2) partner link, (3) partners, (4) variables, (5) correlation sets, (6) fault handlers, (7) compensation handlers and event handlers.

BPMN (Business Process Modelling Notation) is a set of standard about business processes symbol mark developed by BPMI (The Business Process Management Initiative). It is maintenance and management by OMG (Object Management Group). The primary goal of BPMN is to provide a notation that is readily understandable by all business users, from the business analysts that create the initial drafts of the processes, to the technical developers responsible for implementing the technology that will perform those processes, and finally, to the business people who will man-age and monitor those processes. Thus, BPMN creates a standardized bridge for the gap between the business proc-ess design and process implementation. The graphical aspects of the notation were organized into specific categories. The five 
basic categories of elements are: flow objects, data, connecting objects, swim- lanes and artifacts. The basic elements are shown in table 2.

\begin{tabular}{|c|c|c|}
\hline Element & Description & Notation \\
\hline Event & $\begin{array}{l}\text { An Event is something that "happens" during the course of a } \\
\text { Process or a Choreography. These Events affect the flow of the } \\
\text { model and usually have a cause (trigger) or an impact (result). } \\
\text { Events are circles with open centres to allow internal markers to } \\
\text { differentiate different triggers or results. There are three types of } \\
\text { Events, based on when they affect the flow: Start, Intermediate, } \\
\text { and End. }\end{array}$ & \\
\hline Activity & $\begin{array}{l}\text { An Activity is a generic term for work that company performs in } \\
\text { Process. An Activity can be atomic or non-atomic (compound). } \\
\text { The types of Activities that are a part of a Process Model are: Sub- } \\
\text { Process and Task, which are rounded rectangles. Activities are } \\
\text { used in both standard Processes and in Choreographies. }\end{array}$ & \\
\hline Gateway & $\begin{array}{l}\text { A Gateway is used to control the divergence and convergence of } \\
\text { Sequence Flow in a Process and in Choreography. Thus, it will } \\
\text { determine branching, forking, merging, and joining of paths. In- } \\
\text { ternal markers will indicate the type of behaviour control }\end{array}$ & \\
\hline $\begin{array}{l}\text { Sequence } \\
\text { Flow }\end{array}$ & $\begin{array}{l}\text { A Sequence Flow is used to show the order that Activities will be } \\
\text { performed in a Process and in a Choreography }\end{array}$ & \\
\hline Message Flow & $\begin{array}{l}\text { A Message Flow is used to show the flow of Messages between } \\
\text { two Participants that are prepared to send and receive them. In } \\
\text { BPMN, two separate Pools in a Collaboration Diagram will } \\
\text { represent the two Participants (e.g., Partner Entities and/or Partner } \\
\text { Roles). }\end{array}$ & \\
\hline Association & $\begin{array}{l}\text { An Association is used to link information and Artifacts with } \\
\text { BPMN graphical elements. Text Annotations and other Artifacts } \\
\text { can be Associated with the graphical elements. An arrowhead on } \\
\text { the Association indicates a direction of flow (e.g., data), when } \\
\text { appropriate. }\end{array}$ & \\
\hline Pool & $\begin{array}{l}\text { A Pool is the graphical representation of a Participant in Collabo- } \\
\text { ration. It is also acts as a "swimlane" and a graphical container for } \\
\text { partitioning a set of Activities from other Pools, usually in the } \\
\text { context of B2B situations. }\end{array}$ & i \\
\hline Lane & $\begin{array}{l}\text { A Lane is a sub-partition within a Process, some-times within a } \\
\text { Pool, and will extend the entire length of the Process, either verti- } \\
\text { cally or horizon-tally. Lanes are used to organize and categorize } \\
\text { Activities. }\end{array}$ & $\sqrt{1}$ \\
\hline Data Object & $\begin{array}{l}\text { Data Objects provide information about what Activities require to } \\
\text { be performed and/or what they produce, Data Objects can } \\
\text { represent a singular object or a collection of objects. Data Input } \\
\text { and Data Output provide the same information for Processes. }\end{array}$ & \\
\hline Group & $\begin{array}{l}\text { A Group is a grouping of Activities that are within the same Cate- } \\
\text { gory (see page } 89 \text { ). This type of grouping does not affect the Se- } \\
\text { quence Flow of the Activities within the Group. The Category } \\
\text { name appears on the diagram as the group label. Categories can be } \\
\text { used for documentation or analysis purposes. Groups are one way } \\
\text { in which Categories of objects can be visually displayed on the } \\
\text { diagram. }\end{array}$ & $\left(\begin{array}{ccc}- \\
\vdots \\
\vdots \\
\vdots \\
-\end{array}\right.$ \\
\hline Annotation & $\begin{array}{l}\text { Text Annotations are a mechanism for a modeller to provide addi- } \\
\text { tional text information for the reader of a BPMN Diagram. }\end{array}$ & \\
\hline
\end{tabular}

Table 2: Basic BPMN Modeling Elements. 
Above show the methods of e-Mod. ARIS is not an open standard. ANSI system processes symbols spread wider, more suitable for computer systems, but is not good ideal for the emphasis on the management of business processes. IDEF notation biased information systems modelling. UML comparison focuses on programmers and particularly good at objectoriented software development, but in the communication between business management, it is difficulty. BPEL / BPMN are suitable for business analysis by managers. It is based on open standards without manufacturer restrictions. So I recommend using it modelling the e-Mod.

\subsection{Select the Modelling Method of e- Mod}

Hammer (1996) that e-Mod model is a description of actual process logic that eBusiness system creates value [13]. So, the e-Mod modelling can be express by business process. In other words, by business process modelling, we can implement the e-Mod modelling.

Using business process modelling has the following advantages:

- Can be closely combined with the actual operation of enterprises (online-style), but not abstract, from the operation of the process (outline-style) of the theoretical analysis.

- Business process can be executed and monitored, with practica.

- Business processes can be easily integrated to the development system, or application system. In order to align business and IT, forming the business-drived system.

- Business processes can be integrated the the business logic (including business rules), business metrics (such as KPI), business resources (such as human, financial, time) and so on. It can be control in the process operation, also can be continuous improvement by monitoring and statisticsing. If the accumulated wealth of data, It can provid financial and excution of performance assessment in the design.

- Flexibility on-demand.

\section{INTERFACE OF E-MODE}

The e-Mod modelling using BPEL can be implement ap-plication with the SOA, and in the form of Web services published on the web. Web services publishing and request way as shown in Fig 2. They are exchanging information through the WSDL file.

WSDL describes the Web service's public interface. It is an XML-based language for describing network services as a set of endpoints operating on messages containing either document-oriented or procedure-oriented information. The operations and messages are described abstractly, and then bound to a concrete network protocol and message format to define an endpoint. Related concrete endpoints are com-bined into abstract endpoints (services). WSDL is extensible to allow description of endpoints and their messages regard-less of what message formats or network protocols are used to communicate. WSDL 2.0 became a W3C recommenda-tion on June 2007. Use of WSDL interface, the e-Mod in-formation can be described so that the requester understands the e-Mod. The WSDL document construction is shown in table 3 .

In WSDL document, the 'documentation element' is an optional element used for human-readable or machineprocessable document containers. The element contents may be any text and XML Schema compound elements. You can take advantage of the document to embed e-Mod framework the description, as shown in Table 4. 


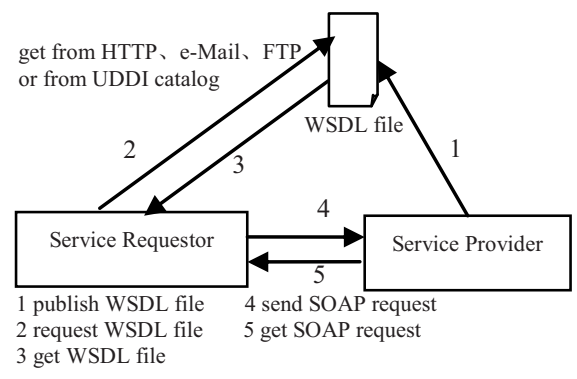

Fig. 2: Web service request-service relationship.

$<$ wsdl:definitions name="nmtoken"? targetNamespace="uri"?>

$<$ import namespace="uri" location="uri"/>*

$<$ wsdl:documentation .... $/>$ ?

$<$ wsdl:types ..../> ?

$<$ wsdl:message .... $>$ *

$<$ wsdl:portType .... $/>^{*}$

$<$ wsdl:binding .... $>*$

$<$ wsdl:service .... $/>*$

$</$ wsdl:definitions $>$

Table 3: WSDL document construction.

$<$ wsdl:documentation .... $>>$

$<$ FunctionalDescription $>$

$<$ ModelNmae .... $>>$

$<$ ModelType .... $/>$

$<$ IndustryCategory.../>

$<$ FunctionalDescription $>$

$<$ ValueProposition ... $>$

$<$ MarketPosit-Segmentation .... $/>$

$<$ RevenueModel .... $/>$

$<$ CoreCapabilities .... $>>$

$<$ ValueChainNetStruc-Posit .... $>>$

$</$ wsdl:documentation $>$

Table 4: e-Mod description embed in WSDL.

\section{DEMONSTRATION}

This is a demonstration about travel order. A series of re-lated companies such as the airlines, the hotels, the sightsee tours, the car rentals and so on are organized by the business process chart to form the travel value chain. Fig 3 is the business process diagram, and Table 5 is the process described by PBEL Language. Table 6 is the WSDL.

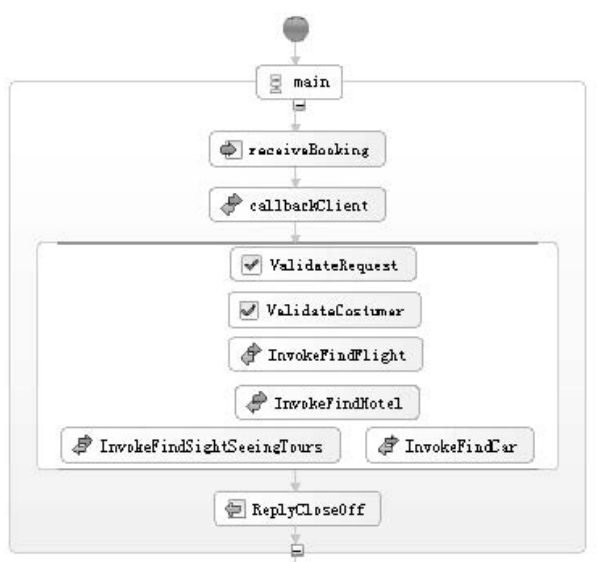

Fig. 3: The BPMN business process.

$<$ ?xml version="1.0" encoding="UTF-8"?>

$<$ bpws:process exitOnStandardFault="yes" name $=$ "TravleOrder"

suppressJoinFailure="yes" targetNamespace="http://eclipse.org/bpel"

xmlns:bpws="http://docs.oasis-

open.org/wsbpel/2.0/process/executable"

xmlns:tns="http://eclipse.org/bpel">

$<$ bpws:import import-

Type="http://schemas.xmlsoap.org/wsdl/"

location="TravleOrder.wsdl" names-

pace="http://eclipse.org/bpel"/>

$<$ bpws:partnerLinks $>$

$<$ bpws:partnerLink myRole="TravleChainProvider" name $=$ "client"

partnerLinkType $=$ "tns:TravleChain" partner-

Role="TravleChainRequester"/>

$<$ bpws:partnerLink name="PartnerLink"/>

$<$ /bpws:partnerLinks $>$

$<$ bpws:variables $>$

$<$ bpws:variable message-

Type $=$ "tns:TravleChainRequestMessage"

name $=$ "input" $>>$

$<$ bpws:variable message-

Type="tns:TravleChainResponseMessage" name="output" $/>$

$<$ bpws:variables $>$

$<$ bpws:sequence name="main" $>$

$<$ bpws:receive createInstance="yes"

name="receiveBooking"

operation="initiate" partnerLink="client"

portType="tns:TravleChain" variable="input"/>

bpws:invoke inputVariable="output"

name $=$ "callbackClient"

operation="onResult" partnerLink="client"

portType="tns:TravleChainCallback"/> 


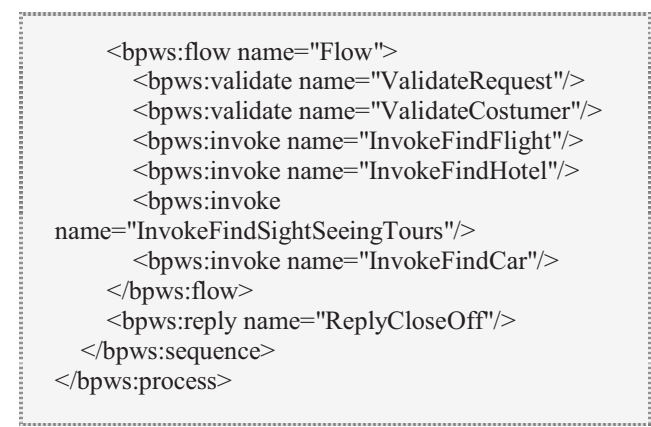

Table 5: The BPEL Language.

$<$ ?xml version="1.0" encoding="UTF-8"?>

$<$ definitions

xmlns:tns="http://TravleOrder/TravleOrderProcessInter face"

xmlns:xsd="http://www.w3.org/2001/XMLSchema" xmlns="http://schemas.xmlsoap.org/wsdl/" name $=$ "TravleOrderProcess" targetNamespace $=" \mathrm{http}: / /$ TravleOrder/TravleOrderProcessInterface" $>$

$<$ documentation $>$

$<$ Functional Description $>$

$<$ ModelNmae $>$

$<$ ModelName $>$ "TravleOrder"

$<$ ModelType $>$ "B2C" $<$ /ModelType $>$

$<$ IndustryCategory $>$ "GICS 25301020"

$<$ /Industrycategory $>$

$<$ /Functional Description $>$

$<$ ValueProposition $><$ /ValueProposition $>$

$<$ MarketPositSegmentation $>$

$<$ /MarketPositSegmentation $>$

$<$ RevenueModel $><$ /RevenueModel $>$

$<$ CoreCapabilities $><$ /CoreCapabilities $>$

$<$ ValueChainNetStruc-Posit $>$

$<$ /ValueChainNetStruc-Posit $>$

$<$ documentation $>$

$<$ types $>\ldots . .</$ types $>$

$<$ message name="operation 1 Request" $>\ldots<$ message $>$

$<$ message

name="operation 1 Response" $>$. . $</$ message $>$

$<$ portType name="TravleOrderProcess" $>$

$<$ operation $>\ldots \ldots .<$ operation $>$

$<$ portType $>$

$</$ definitions

Table 6: WSDL interface.

\section{CONCLUSIONS}

In summary, enterprise e-Business model needs informationization, that is digital model (e-Mod). The e-Mod can be con- structed by the theory of e-business elements. The digitized model description can be implemented through BPEL/BPMN. This form of e-Mod can be published on the Internet by the Web service approach for machine to understand, and further implemented the application through the SOA methodology.

\section{ACKNOWLEDGMENT}

This research was supported by the eBusiness Innova-tion Center of YUFE.

\section{REFERENCES}

[1] B.Mahadevan(2000), Business Models for Internet-Based E-Commerce: An Anatomy. California Management Review, (4):55-69.

[2] Russell Thomas, Business Value Analysis: Coping with Unruly Uncertainty . Strategy \& Leadership , 2001,29(2):16-23.

[3] Afuah A., Tucci C. Internet Business Models and Strategies. New York : McGraw-Hill International Editons, 2001

[4] Yves Pigneur, The e-Business Model Handbook[Z]. http://inforge.unil.ch/yp/Pu b/oo-ebmh.pdf, 2002 .

[5] Magali Dubsson-Toray, Alexander Osterwalder \& Yves Pigneur, eBusiness Model Design, Classification and Measurements $[\mathrm{J}]$. Thunderbird International Business Review, 2001(4).

[6] Lynda M. Applegate, Emerging eBusiness Models: Lessons from the Field[Z] . http://WWW.stuart.iit.edu/ courses/ecom530/fall2001/bmodels2. pdf, 2001-7-26.

[7] Henry Chesbrough and Richard S. Rosenbloom. The Role of the Business Model in Capturing Value 
from Innovation:Evidence from Xerox Corporation's Technology Spinoff Companies[Z] . http://www.hbs.edu/dor/pap ers2/0001/01-002.pdf, 2001-11-16.

[8] Rainer A1t, Hans-Dieter Zimmermann. Preface: Introduction to Special Section-Business Models $[\mathrm{J}]$. Electronic Markets , 2001,11(1):3-9.

[9] Jane Linder and Susan Cantrell. What makes a good business model anyway? Can yours stand the best test of change?[Z]. http://www.accenture.com/xdoc/en/id eas outlook/pov/business_model_pov.pdf,20 01 .

[10] Faisal Hoque and Paul Gulbin. Can you solve the Business-Technology
Disconnect[J] . e-Business Advisor,2001(2).

[11] J . Hedman and Thomas Kalling. The business model; A means to understand the business context of information and communication technology[Z]. Working paper,2001-9.

[12] Mckey J., P. Marshall. Strategic Management of E-Business. Milton, Qld., Australia: John Wiley and Sons, 2004

[13] Global Industry Classification Standard]Z\}. http://www.mscibarra.com/products/i ndices/gics/

[14]14. Michael Hammer(1996).Reengineering: how the process-centered organization is changing our work and our lives. New York: HarperCollins Publishers 